\title{
Frequency of bacterial isolates and antibiotics resistance patterns in urine and pus samples.
}

1. Ph.D

Associate Professor Biotechnology Abdul Wali Kahn University, Mardan

2. Ph.D Biotechnology Student

Abdul Wali Kahn University, Mardan.

3. FCPS

Professor Medicine

Peshawar Medical College,

Peshawar.

4. M.Phil Pathology (Microbiology) Assistant Professor Pathology Khyber Medical College, Peshawar.

5. M.Phil

Lecturer Department of MLT Bacha Khan Medical College, Mardan.

Correspondence Address: Dr. Anees Muhammad

Medical Laboratory Technology

Mardan College of Medical

Technology,

Bacha Khan Medical College, Mardan aneesafridi15295@yahoo.com

Article received on:

$11 / 08 / 2020$

Accepted for publication: $08 / 02 / 2021$

\section{Sajid Ali ${ }^{1}$, Hina Khaliq ${ }^{2}$, Noor Muhammad ${ }^{3}$, Syed Luqman Shuaib ${ }^{4}$, Anees Muhammad}

ABSTRACT... Objectives: The present study is aimed to determine frequency of bacteria in urine and pus sample along with the antibiotic resistance profile of isolated bacteria. Study Design: Cross-Sectional Study. Setting: Real-Time PCR Laboratory at Dabgari Garden, Peshawar with the Collaboration of Health Biotechnology Laboratory, Department of Biotechnology, Abdul Wali Khan University, Mardan. Period: June 2018 to July 2019. Material \& Methods: The urine and pus samples were collected from suspected patients and were cultured on appropriate culture media. The biochemical tests were also performed after growing on culture plates for identification and confirmation of bacterial isolates. The disc diffusion technique was used to evaluate the antibiotic pattern of retrieved isolates. Result: A total of 525 samples of pus and urine samples were collected from different regions of Peshawar. Out of the total, 237 (45.1\%) samples were found positive for bacterial growth whereas the remaining $(54.9 \%)$ were observed negative. Among total positive isolates, 220 (92.8\%) were from urine samples, and 17 (7.2\%) were from pus samples. The predominant isolate was Escherichia coli (E. coli) $(90.3 \%)$ retrieved from positive samples, followed by Pseudomonas aeruginosa (7.2\%), Klebsiella pneumonia $(1.3 \%)$, and Staphylococcus aureus (1.3\%). The most effective antibiotic was Fosfomycin against bacteria whereas Nalidixic acid, Nitrofurantoin, and Amoxicillin/clavulanic acid were found less effective against bacterial isolates. Conclusion: Most frequent bacteria isolated was E. coli and the most efficient drug was Fosmomycin and the least was Nitrofurantoin, and Amoxicillin.

Key words: $\quad$ Antibiotics, E. Coli, Peshawar, Pus, Uropathogens.

Article Citation: Ali S, Khaliq H, Muhammad N, Shuaib SL, Muhammad A. Frequency of bacterial isolates and antibiotics resistance patterns in urine and pus samples. Professional Med J 2021; 28(11):1571-1577. https://doi.org/10.29309/TPMJ/2021.28.11.5987

\section{INTRODUCTION}

Antibacterial drugs are necessary for the protection of public health from bacterial infections. However, antibiotic resistance is becoming a challenge for public health and health professionals. ${ }^{1}$ The high proportion of bacterial infection including bloodstream infection along with other related diseases needs special attention. ${ }^{2}$ The frequency of bacterial infection caused by resistant bacterial isolates were more than $50 \%{ }^{3}$ From the last few decades, antimicrobial-resistant is increasing continuously. ${ }^{4}$ The management of bacterial infection is critically associated with specific and appropriate antibiotics. The bacterial infections caused by resistant isolates are the leading public health issue. Many categories of drugs currently exist for the treatment and management of bacterial infections including Aminoglycosides, Cephalosporin (various classes), Fluoroquinolones, Macrolides, Penicillin, and Tetracycline. ${ }^{5}$

The predominant isolates of urine and pus are highly resistant to antibiotics such as Carbapenem. ${ }^{6}$ Various mechanisms are related to bacterial resistance against antibiotics are known including enzyme-producing bacteria (Metallo beta-lactamases and extendedspectrum beta-lactamases). ${ }^{7}$ The mechanism of resistance to carbapenems such as efflux pumps, producing carbapenemase, and porins actions are frequently associated. ${ }^{8}$ Mostly gram-negative bacterial isolates show resistance to antibiotics due to enzymes. ${ }^{9,10}$ 
The Enterobacteriaceae family is primarily involved in bacterial infection particularly in urinary tract infections. The common resistance caused by Escherichia coli (E. coli), Klebsiella pneumonia (K. pneumoniae), Pseudomonas aeruginosa (P. aeruginosa), and Staphylococcus aureus (S. aureus) related to antibiotics due to misuse of antibiotics, an overdose of drugs, nonadherence, and non-compliance..$^{11,12}$ The purpose of the study was to find out bacterial isolates in urine and pus samples and the most efficient drug used against these bacterial isolates.

\section{MATERIAL \& METHODS}

The cross-sectional study was conducted in Real-Time PCR Laboratory at Dabgari Garden, Peshawar with the Collaboration of Health Biotechnology Laboratory, Department of Biotechnology, Abdul Wali Khan University, Mardan. The study duration was from June 2018 to July 2019. A total of 525 samples were collected. Simple conveinent technique was used for sample collection.

\section{Inclusion Criteria}

All volunteer patients were included irrespective of age and gender.

\section{Exclusion Criteria}

Non-volunteer and samples other than urine and pus were excluded.

The collected samples of pus and urine were transported to the laboratory and were cultured on their specific media such as MacConkey agar, Blood agar, and Cysteine Lactose Electrolyte Deficient (CLED) agar. The bacterial growth was determined after 18-24hours. The bacterial isolates were further processed through biochemical tests for identification and confirmation of grampositive and gram-negative bacterial isolates. The gram staining procedure was applied for the identification of bacteria and was examined under the $100 \mathrm{X}$ lens of microscope. ${ }^{13,14}$

The morphological colonies of E. coli, P. aeruginosa, $\mathrm{K}$. pneumoniae, and $\mathrm{S}$. aureus were identified as per the recommended protocol. ${ }^{15}$ The disc diffusion method was used for antibiotics susceptibility testing. The Muller Hinton Agar was used for the disc diffusion technique. ${ }^{16}$ Several locally available antibiotics discs were used including Amikacin $(30 \mu \mathrm{g})$, Ampicillin $(10 \mu \mathrm{g})$, Amoxicillin-clavulanic acid (20/10 $\mu$ g), Ceftazidime $(30 \mu \mathrm{g})$, Ceftriaxone $(30 \mu \mathrm{g})$, Ciprofloxacin $(5 \mu \mathrm{g})$, Clindamycin $(2 \mu \mathrm{g})$, Cotrimoxazole $(1.25 \mu \mathrm{g})$, Gentamicin $(10 \mu \mathrm{g})$, Imipenem $(10 \mu \mathrm{g})$, Methicillin

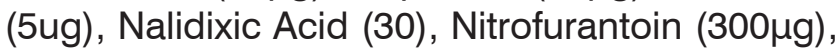
Oxacillin $(1 \mu \mathrm{g})$, and Vancomycin $(30 \mu \mathrm{g}) .{ }^{17}$

Microsoft Excel 2007 was used for the initial analysis of data, which was further analyzed by statistical package for social science version 22. Ethical approval for study was obtained from Abdul Wali Khan University, Mardan (AWKUM/ Biotech/2018/806).

\section{RESULTS}

A total of 525 samples were collected from patients irrespective of age, gender, and ethnicity. Out of total, $88.0 \%(n=462)$ were urine samples, while $12.0 \%(n=63)$ were pus samples. Among the total samples $(n=525), 45.1 \%(n=237)$ were found positive and showed bacterial growth while remaining were negative. Among the positive culture, 92.8\% $(n=220)$ and $7.2 \%(n=17)$ were observed in urine and pus samples respectively (Table-l).

\begin{tabular}{|l|c|c|}
\hline \multicolumn{1}{|c|}{ Samples } & Culture & $\begin{array}{c}\text { Percentage } \\
\text { (Frequency) \% (n) }\end{array}$ \\
\hline $\begin{array}{l}\text { Urine Sample } \\
(\mathrm{n}=462)\end{array}$ & Positive & $47.6(220)$ \\
\hline \multirow{2}{*}{$\begin{array}{l}\text { Pus Sample } \\
(\mathrm{n}=63)\end{array}$} & Negative & $52.4(242)$ \\
\hline \multirow{2}{*}{ Total } & Positive & $27.0(17)$ \\
\hline \multirow{2}{*}{ Table-I. Frequency of culture-positive and negative in } \\
\cline { 2 - 3 } \\
\cline { 2 - 3 }
\end{tabular}

The frequency of bacterial isolates was also evaluated in both pus and urine specimens of patients. The proportion of bacterial isolates including E. coli, P. aeruginosa, K. pneumoniae, and $S$. aureus was $90.3 \%, 7.2 \%, 1.3 \%$, and $1.3 \%$ respectively, in urine and pusspecimens. The most 
common uropathogen was E. coli, determined in $93.6 \% \quad(n=206)$ urine samples, followed by $\mathrm{P}$. aeruginosa $(5 \%)$, and $\mathrm{K}$. pneumoniae (1.4\%). Similarly, E. coli was also predominantly ascertained in $47.1 \%$ pus samples, followed by P. aeruginosa (35.3\%) and S. aureus (17.6\%) (Table-II).

The antibiotic susceptibility patterns of different isolates were determined, using available antibiotics. The E. coli showed the highest resistance to Nalidixic acid (83\%), followed by Nitrofurantoin (75\%), Norfloxacin (75\%), Cefotaxime, Ceftriaxone, Ciprofloxacin and Ceftazidime (67\% each). However, Meropenem, Amikacin, and Fosfomycin and Piperacillin/ Tazobactam were the most effective antibiotic against E. coli with a proportion of $99 \%, 99 \%$, 98\% and $96 \%$ respectively (Table-III).

P. aeruginosa showed high resistance to Nitrofurantoin (100\%), followed by Amoxicillin/

Clavulanic Acid (99\%), Nalidixic acid (81\%), and Ceftriaxone (71\%). Whereas, highly susceptible to Amikacin (100\%), Meropenem (100\%), and Tazobactam/Pipercillin (100\%), Fosfomycin (76\%), Ceftazidime (64\%) and Ciprofloxacin (59\%) (Table-III).

The K. pneumoniae were highly resistant to Nitrofurantoin (100\%), followed by Cefotaxime, Piperacillin, Nalidixic acid, Ceftriaxone, and Ciprofloxacin. The most effective antibiotics were Meropenem, Aztreonam, Fosfomycin, Amikacin, Norfloxacin, and Piperacillin/ Tazobactam (TableIII).

S. aureus was predominantly resistant to Aztreonam (100\%), Nalidixic acid (100\%), Piperacillin (100\%), and Amoxicillin/Clavulanic Acid (100\%). Whereas, the highly effective antibiotics were fosfomycin having $0 \%$ resistance, followed by Ceftriaxone, Cefotaxime, Ceftazidime, and Amikacin (Table-III).

\begin{tabular}{|l|c|c|c|c|c|}
\hline \multicolumn{1}{|c|}{ Sr. No. } & $\begin{array}{c}\text { E. coli } \\
\text { \% (n) }\end{array}$ & $\begin{array}{c}\text { P. aeruginosa } \\
\%(\mathbf{n})\end{array}$ & $\begin{array}{c}\text { K. pneumoniae } \\
\%(\mathbf{n})\end{array}$ & $\begin{array}{c}\text { S. aureus } \\
\%(\mathbf{n})\end{array}$ & $\begin{array}{c}\text { Total } \\
\%(\mathbf{n})\end{array}$ \\
\hline Urine & $93.6(206)$ & $5.0(11)$ & $1.4(03)$ & $0(0)$ & $92.8(220)$ \\
\hline Pus & $47.1(08)$ & $35.3(06)$ & $0(0)$ & $17.6(03)$ & $7.2(17)$ \\
\hline Total & $90.3(214)$ & $7.2(17)$ & $1.3(03)$ & $1.3(03)$ & $100(237)$ \\
\hline
\end{tabular}

Table-II. Comparative occurence of bacteria (E. coli, P. aeruginosa, K. pneumoniae, and S. aureus) in both urine and pus samples.

\begin{tabular}{|c|c|c|c|c|c|}
\hline Sr. No. & Antibiotics & E. Coli \% & P. aeruginosa \% & K. pneumonia \% & S. aureus $\%$ \\
\hline 1 & Aztreonam & 62 & 53 & 33 & 100 \\
\hline 2 & Fosfomycin & 2 & 24 & 33 & 0 \\
\hline 4 & Ceftriaxone & 67 & 71 & 67 & 0 \\
\hline 5 & Ciprofloxacin & 67 & 41 & 67 & 67 \\
\hline 7 & Meropenem & 1 & 0 & 0 & 67 \\
\hline 8 & Amikacin & 1 & 0 & 33 & 33 \\
\hline 9 & Nalidixic Acid & 83 & 81 & 67 & 100 \\
\hline 10 & Norfloxacin & 75 & 56 & 33 & - \\
\hline 11 & Piperacillin/ Tazobactam & 4 & 0 & 33 & 67 \\
\hline 15 & Amoxicillin/ Clavulanic Acid & 55 & 99 & 33 & 67 \\
\hline
\end{tabular}

Table-III. Antibiotic-resistant pattern of E. coli, P. aeruginosa, K. pneumoniae and S. aureus collected from urine and pus samples. 


\section{DISCUSSION}

Frequency and pattern of antibiotic-resistant were determined in the present study. The results of the study show that the culture-positive proportion was found in $45.1 \%$ samples both in urine and pus. The proportion of gram-negative bacteria was more than gram-positive bacteria in the present study. Similar to the current study, a study revealed from China conducted during 2015-2018, which shows a $43 \%$ prevalence of bacterial isolates in clinical samples, in which gram-negative bacterial isolates was $88 \% .^{18,19}$ The result of the present study is also in accordance with the other study carried out in Pakistan. ${ }^{20}$

This study results also revealed that the percentage of E. coli, P. aeruginosa, K. pneumoniae, and S. aureus was $90.3 \%, 7.2 \%, 1.3 \%$, and $1.3 \%$ respectively. In the earlier studies, a similar report revealed that the growth of E. coli, P. aeruginosa, $\mathrm{K}$. pneumoniae, and $\mathrm{S}$. aureus were observed in $73 \%, 7 \%, 1.5 \%$, and $1 \%$, respectively. ${ }^{21}$ Our results are in accordance with a previous study in which infections due to E. coli was $90 \%$ while other microorganisms causing UTI were only $10 \%$. The rate of resistance was $50.6 \%$ while $45 \%$ culture positivity which is similar to the finding of a study carried in China. ${ }^{22}$

The study carried out in 2015, which shows that the resistance of E. coliagainst Amikacin, Amoxicillin/ Clavulanic acid, Ampicillin, and Aztreonam was $91 \%, 84 \%, 84 \%$, and $72 \%$ respectively. ${ }^{23}$

The present study shows that E. coli was highly resistant to eight different antibiotics including Nalidixic acid, Nitrofurantoin, and Norfloxacin. Similar to other studies conducted by various researchers in a different region of the world showed the highest susceptibility to Fosfomycin, Imipenem, Meropenem, and Piperacillin/ Tazobactam. ${ }^{24}$

In the current study, the sensitivity of E. coli was Amikacin, Meropenem, Fosfomycin, and Piperacillin/Tazobactam was 99\%, 99\%, 98\%, and $96 \%$ respectively. P. aeruginosa was found the second most common gram-negative bacterial isolates in urine and pus samples, which shows frequent resistance to Nitrofurantoin, Amoxicillin/ Clavulanic acid, Nalidixic acid, and Ceftriaxone. On the other hand, most efficient antibiotics were Amikacin, Meropenem, and Tazobactam/ Piperacillin against the second most prevalent bacteria. K. pneumoniae showed less resistance as compared to P. aeruginosa. The Meropenem and Amikacin were found most effective antibiotic against $\mathrm{K}$. pneumoniae with $0 \%$ (zero) resistance, while found less efficient antibiotics were Nitrofurantoin, Nalidixic acid, and Ceftriaxone. In the previous studies, the proportion of resistance was high against Norfloxacin and Ciprofloxacin. ${ }^{25}$ A study also revealed a $100 \%$ sensitivity of Nitrofurantoin against K. pneumonia. ${ }^{16}$ The S. aureus was found only gram-positive bacterial isolate in the present study, which is 100\% resistant to Aztreonam, Ceftizoxime, Nalidixic acid, and Piperacillin. However, Fosfomycin and Ceftriaxone was $100 \%$ effective against S. aureus. These findings of the present were consistent with previously conducted studies, which revealed that Amikacin is a highly sensitive antibiotic. ${ }^{26}$ On the other side, the resistance of S. aureus was noted against Ampicillin, Amoxicillin, Ciprofloxacin, Levofloxacin, and Norfloxacin. ${ }^{27}$ Another study revealed that Nitrofurantoin was the most efficient antibiotic. ${ }^{28}$ According to previousreports, the resistance against antibiotics from 2005 to 2014 was similar to the present study. ${ }^{29} \mathrm{~A}$ recent study in China conducted showed that the resistance proportion was consistent with both gramnegative bacteria and gram-positive bacteria. ${ }^{30,31}$ A study showed $50 \%$ resistance to P. aeruginosa for a wide range of antibiotics. ${ }^{32}$ In a past study conducted in India observed that the Amikacin (99.6\%), Nitrofurantoin (91\%), and Ciprofloxacin $(88 \%)$ was susceptible ${ }^{33}$ which is similar to the results of Amikacin but discord with results the Ciprofloxacin and Nitrofurantoin, which was $0 \%$ (zero) in the study.

A few limitations were also found with current study, molecular determination was not study of isolated isolates, clinical demographic data and samples other than urine and pus were not studied. 


\section{CONCLUSION}

In summary, the frequency of $\mathrm{E}$. coli infection was greater than the rest of the gram-negative isolates. In the gram-positive isolates, $\mathrm{S}$. aureus was found only bacterial isolate. Overall, the rate of growth of gram-positive was $1.3 \%$ whereas the gram-negative strains were $98.7 \%$. The antibiotics resistance pattern was also observed, where E. coli, P. aeruginosa and K.pneumoneae were susceptible $100 \%$ to Amikacin and Meropenem along with the Piperacillin/Tazobactam against all three gram-negative species. Fosfomycin was most effective against the retrieved bacteria. Based on the current finding, proper management is essential to overcome the resistance of antibiotics. The periodic surveillance of antibiotics is highly recommended to determine the pattern of resistance of antibiotics.

\section{Conflict of Interest}

Authors have no conflict of interest.

\section{Copyright $\odot 08$ Feb, 2021.}

\section{REFERENCE}

1. Onifade AK, Alaofin S, Owoyemi OO. Isolation and characterization of plasmid-bearing multiple antibiotic resistance bacteria from different aquatic sources in Akure, Nigeria. Microbiol. Res. J. Int. 2019 Apr 20:1-12. DOI:10.9734/mrii/2019/v27i430103.

2. Anwar M, Ejaz H, Zafar A, Hamid H. Phenotypic detection of metallo-beta-lactamases in carbapenem resistant Acinetobacter baumannii isolated from pediatric patients in Pakistan. J. Path. 2016 Mar 30; 2016. https://doi.org/10.1155/2016/8603964.

3. Ansari MA, Shaikh S, Shakil S, Rizvi SM. An enzoinformatics study for prediction of efficacies of three novel penem antibiotics against New Delhi metallo- $\beta$-lactamase-1 bacterial enzyme. Interdiscip Sci.: Comput. L. Sci. 2014 Sep 1; 6(3):208-15. DOI: 10.1007/s12539-013-0202-9.

4. Arnold RS, Thom KA, Sharma S, Phillips M, Johnson $\mathrm{JK}$, Morgan DJ. Emergence of Klebsiella pneumoniae carbapenemase (KPC)-producing bacteria. South Med J. 2011 Jan; 104(1):40-45. DOI: 10.1097/ SMJ.0b013e3181fd7d5a.
5. Bratu S, Landman D, Haag R, Recco R, Eramo A, Alam M, Quale J. Rapid spread of carbapenem-resistant Klebsiella pneumoniae in New York City: A new threat to our antibiotic armamentarium. Arch Intern Med. 2005 Jun 27; 165(12):1430-5. DOI: 10.1001/ archinte.165.12.1430.

6. Carvalhaes CG, Picao RC, Nicoletti AG, Xavier DE, Gales AC. Cloverleaf test (modified Hodge test) for detecting carbapenemase production in Klebsiella pneumoniae: $\mathrm{Be}$ aware of false positive results. J. Antimicrob. Chemother. 2010 Feb 1; 65(2):249-51. DOI: $10.1093 / \mathrm{jac} / \mathrm{dkp} 431$.

7. Chen L, Mathema B, Chavda KD, DeLeo FR, Bonomo RA, Kreiswirth BN. Carbapenemase-producing Klebsiella pneumoniae: Molecular and genetic decoding. Trends Microbiol. 2014 Dec 1; 22(12):68696. DOI: 10.1016/j.tim.2014.09.003.

8. Doménech-Sánchez A, Hernández-Allés S, MartínezMartínez L, Benedí VJ, Albertí S. Identification and characterization of a new porin gene of Klebsiella pneumoniae: Its role in $\beta$-lactam antibiotic resistance. J. Bacteriol. 1999 May 1; 181 (9):2726-32. DOI: 10.1128/ JB.181.9.2726-2732.1999.

9. Doumith M, Ellington MJ, Livermore DM, Woodford N. Molecular mechanisms disrupting porin expression in ertapenem-resistant Klebsiella and Enterobacter spp. clinical isolates from the UK. J. Antimicrob. Chemother. 2009 Apr 1; 63(4):659-67.

10. Lautenbach E, Strom BL, Bilker WB, Patel JB, Edelstein $\mathrm{PH}$, Fishman NO. Epidemiological investigation of fluoroquinolone resistance in infections due to extended-spectrum $\beta$-lactamase-producing Escherichia coli and Klebsiella pneumoniae. Clin. Infect. Dis. 2001 Oct 15; 33(8):1288-94.

11. Forbes, L. "Rapid Flagella Stain." J Clin Microbiol 13, no. 4 (Apr 1981): 807-9. DOI: 10.1128/jcm.13.4.807809.1981 .

12. Gottlieb T, Nimmo GR. Antibiotic resistance is an emerging threat to public health: An urgent call to action at the Antimicrobial Resistance Summit 2011. Med J Aust. 2011 Mar 21; 194(6):281-3. DOI: 10.5694/ j.1326-5377.2011.tb02973.x.

13. Gu DX, Huang YL, Ma JH, Zhou HW, Fang Y, Cai JC, Hu YY, Zhang R. Detection of colistin resistance gene mcr-1 in hypervirulent Klebsiella pneumoniae and Escherichia coli isolates from an infant with diarrhea in China. Antimicrob. Agents Chemother. 2016 Aug 1; 60(8):5099-100. Doi: 10.1128/AAC.00476-16.

14. Jarvis RM, Goodacre R. Characterisation and identification of bacteria using SERS. Chem. Soc. Rev. 2008; 37(5):931-6. DOI: 10.1039/b705973f. 
15. Kalanetra KM, Bano N, Hollibaugh JT. Ammonia $\square$ oxidizing Archaea in the Arctic Ocean and Antarctic coastal waters. Environ Microbiol. 2009 Sep; 11 (9):2434-45. DOI: 10.1111/j.1462-2920.2009.01974.x.

16. Kumar R, Yadav BR, Singh RS. Antibiotic resistance and pathogenicity factors in Staphylococcus aureus isolated from mastitic Sahiwal cattle. J. biosci. 2011 Mar 1; 36(1):175-88. DOI: 10.1007/s12038-011-9004-6.

17. Lee K, Park AJ, Kim MY, Lee HJ, Cho JH, Kang JO, Yong D, Chong Y, KONSAR group. Metallo- $\beta$-lactamaseproducing Pseudomonas spp. in Korea: High prevalence of isolates with VIM-2 type and emergence of isolates with IMP-1 type. Yonsei Med. J. 2009 Jun 30; 50(3):335-9. DOI: 10.3349/ymj.2009.50.3.335.

18. Martinez-Morales F, Borges AC, Martinez A, Shanmugam KT, Ingram LO. Chromosomal integration of heterologous DNA in Escherichia coli with precise removal of markers and replicons used during construction. J. Bacteriol. 1999 Nov 15; 181 (22):71438. DOI: 10.1128/JB.181.22.7143-7148.1999.

19. Paczosa MK, Mecsas J. Klebsiella pneumoniae: Going on the offense with a strong defense. Microbiol Mol Biol Rev. 2016 Sep 1; 80(3):629-61. DOI: 10.1128/ MMBR.00078-15.

20. Papp-Wallace KM, Bethel CR, Distler AM, Kasuboski $\mathrm{C}$, Taracila M, Bonomo RA. Inhibitor resistance in the KPC-2 $\beta$-lactamase, a preeminent property of this class A $\boldsymbol{\beta}$-lactamase. Antimicrob. Agents Chemother. 2010 Feb 1; 54(2):890-7. DOI: 10.1128/AAC.00693-09.

21. Paterson DL, Mulazimoglu L, Casellas JM, Ko WC, Goossens H, Von Gottberg A, Mohapatra S, Trenholme GM, Klugman KP, McCormack JG, Yu VL. Epidemiology of ciprofloxacin resistance and its relationship to extended-spectrum $\beta$-lactamase production in Klebsiella pneumoniae isolates causing bacteremia. Clin. Infect. Dis. 2000 Mar 1; 30(3):473-8. DOI: $10.1086 / 313719$.

22. Pitout JD, Nordmann P, Poirel L. Carbapenemaseproducing Klebsiella pneumoniae, a key pathogen set for global nosocomial dominance. Antimicrob. Agents Chemother. 2015 Oct 1; 59(10):5873-84. DOI: 10.1128/AAC.01019-15.

23. Rock C, Thom KA, Masnick M, Johnson JK, Harris AD, Morgan DJ. Frequency of Klebsiella pneumoniae carbapenemase (KPC) and non-KPC-producing Klebsiella contamination of Healthcare workers and the environment. Infect. Control Hosp. Epidemiol. 2014 Apr; 35(4):426. DOI: 10.1086/675598.
24. Sandlund J, Naucler P, Dashti S, Shokri A, Eriksson S, Hjertqvist M, Karlsson L, Capraru T, Färnert A. Bacterial coinfections in travelers with malaria: Rationale for antibiotic therapy. J. Med Micro. 2013 Jan 1; 51(1):1521. doi: 10.1128/JCM.02149-12.

25. Shakil S, Akram M, Ali SM, Khan AU. Acquisition of extended-spectrum $\beta$-lactamase producing Escherichia coli strains in male and female infants admitted to a neonatal intensive care unit: Molecular epidemiology and analysis of risk factors. J. Med Micro. 2010 Aug 1; 59(8):948-54. DOI: 10.1099/ jmm.0.020214-0.

26. Shin SY, Bae IK, Kim J, Jeong SH, Yong D, Kim JM, Lee $\mathrm{K}$. Resistance to carbapenems in sequence type 11 Klebsiella pneumoniae is related to DHA-1 and loss of OmpK35 and/or OmpK36. J. Med Micro. 2012 Feb 1; 61(2):239-45. DOI: 10.1099/jmm.0.037036-0.

27. Sidjabat H, Nimmo GR, Walsh TR, Binotto E, Htin A, Hayashi Y, Li J, Nation RL, George N, Paterson DL. Carbapenem resistance in Klebsiella pneumoniae due to the New Delhi metallo- $\beta$-lactamase. Clin Infect Dis. 2011 Feb 15; 52(4):481. doi: 10.1093/cid/ciq178.

28. Swain SS, Padhy RN. Isolation of ESBL-producing gram-negative bacteria and in silico inhibition of ESBLs by flavonoids. J Taibah Univ Sci. 2016 Jun 1; 11(3):217-29. https://doi.org/10.1016/j. jtumed.2016.03.007.

29. CLSI. Performance standards for antimicrobial susceptibility testing: Approved 28th ed. Document M100-S28. 2018.

30. Wuthiekanun V, Amornchai P, Langla S, White NJ, Day NP, Limmathurotsakul D, Peacock SJ. Antimicrobial disk susceptibility testing of Leptospira spp. using Leptospira Vanaporn Wuthiekanun (LVW) agar. Am J Trop Med Hyg. 2015 Aug 5; 93(2):241-3. DOI: https:// doi.org/10.4269/ajtmh.15-0180.

31. Yigit N, Aktas AE, Ayyildiz A. Detection of coagulase activity in pathogenic Candida species. J. Int. Med Res. 2008 Dec; 36(6):1378-82. DOI: $10.1177 / 147323000803600627$.

32. Yoshida, K., T. Matsumoto, K. Tateda, K. Uchida, S. Tsujimoto, Y. Iwakura, and K. Yamaguchi. Protection against pulmonary infection with Klebsiella pneumoniae in mice by interferon-y through activation of phagocytic cells and stimulation of production of other cytokines. J. Med. Micro. 2001 Nov 1; 50(11):959-64. DOI: 10.1099/0022-1317-50-11959. 
33. Zhang J. Porcine deltacoronavirus: Overview of infection dynamics, diagnostic methods, prevalence and genetic evolution. Virus Res. 2016 Dec 2; 226:7184. DOI: 10.1016/j.virusres.2016.05.028.

\begin{tabular}{|c|c|c|c|}
\hline \multicolumn{4}{|c|}{ AUTHORSHIP AND CONTRIBUTION DECLARATION } \\
\hline No. & Author(s) Full Name & Contribution to the paper & Author(s) Signature \\
\hline 1 & Sajid Ali & $\begin{array}{l}\text { Concept, Design, Clinical studies, } \\
\text { manuscript editing, critical review and } \\
\text { final approval. }\end{array}$ & \\
\hline 2 & Hina Khaliq & $\begin{array}{l}\text { Design, literature review, experimental } \\
\text { studies, manuscript writeup, review } \\
\text { and approval. }\end{array}$ & Wha \\
\hline 3 & Noor Muhammad & $\begin{array}{l}\text { Literature review, data acquisition, } \\
\text { data analysis, manuscript review and } \\
\text { approval. }\end{array}$ & \\
\hline 4 & Syed Luqman Shuaib & $\begin{array}{l}\text { Critical studies, Conceptualization of } \\
\text { study, manuscript writeup, review and }\end{array}$ & Grlaing \\
\hline 5 & Anees Muhammad & $\begin{array}{l}\text { approval. } \\
\text { Literature review, data entry, data } \\
\text { analysis, manuscript writeup, review } \\
\text { and approval. }\end{array}$ & \\
\hline
\end{tabular}

